\title{
Whole-Genome Sequencing of a Year-Round Fruiting Jackfruit Variety Reveals Very High Single Nucleotide Polymorphisms in Inter-Genic Regions
}

Tofazzal Islam ( $\nabla$ tofazzalislam@bsmrau.edu.bd)

Bangabandhu Sheikh Mujibur Rahman Agricultural University (BSMRAU)

Nadia Afroz

Bangabandhu Sheikh Mujibur Rahman Agricultural University (BSMRAU)

ChuShin Koh

University of Saskatchewan

M. Nazmul Haque

Bangabandhu Sheikh Mujibur Rahman Agricultural University (BSMRAU)

Md. Jillur Rahman

Bangladesh Agricultural Research Institute

Dipali Rani Gupta

Bangabandhu Sheikh Mujibur Rahman Agricultural University (BSMRAU)

Nur Uddin Mahmud

Bangabandhu Sheikh Mujibur Rahman Agricultural University (BSMRAU)

Abdullah Al Nahid

Shahjalal University of Science and Technology

Rashedul Islam

University of British Columbia

Pankaj K. Bhowmik

National Research Council of Canada

Andrew G. Sharpe

University of Saskatchewan

\section{Research Article}

Keywords: BARI Kanthal-3, genome sequencing and assembly, heterozygosity, SCOs, SNPs, scaffolds

Posted Date: December 28th, 2021

DOI: https://doi.org/10.21203/rs.3.rs-1176760/v1 
License: (c) (i) This work is licensed under a Creative Commons Attribution 4.0 International License. Read Full License 


\section{Abstract \\ Background}

Jackfruit (Artocarpus heterophyllus Lam.) is a tropical and sub-tropical fruit tree distributed in Asia, Africa, and South America. It is the national fruit of Bangladesh and produces fruit in the summer season only. However, a year-round jackfruit variety, BARI Kanthal-3 developed by Bangladesh Agricultural Research Institute (BARI) provides fruits from September to June. This study aimed to evaluate the agronomic performance of BARI Kanthal-3 and to generate a draft whole genome sequence to obtain molecular insights of this important unique variety.

\section{Results}

Number of fruits, average each fruit weight, fruit yield per plant, edible portion in fruit and $B$ carotene content of BARI Kanthal-3 ( $n=5)$ were 422/plant/year, $5.60 \mathrm{~kg}, 236.32 \mathrm{~kg} / \mathrm{year}, 53.5 \%$ and 3614 $\mathrm{mg} / 100 \mathrm{~g}$, respectively. During de novo assembly, $817.7 \mathrm{Mb}$ of the BARI Kanthal-3 genome was scaffolded. However, in the reference-guided genome assembly, almost $843 \mathrm{Mb}$ of the BARI Kanthal-3 genome was scaffolded. Through BUSCO assessment, $97.2 \%$ of the core genes were represented in the assembly with $1.3 \%$ and $1.5 \%$ either fragmented or missing, respectively. By comparing the single copy orthologues (SCOs) in three closely and one distantly related species of BARI Kanthal-3, 706 SCOs were found to be shared across the genomes of the five species. The phylogenetic analysis of the shared SCOs showed that $A$. heterophyllus is the closest species to BARI Kantal-3. The estimated genome size of BARI Kanthal-3 was 1.04 giga base pairs (Gbp) with a heterozygosity rate of $1.62 \%$. The estimated GC content was $34.10 \%$. Variant analysis revealed that BARI Kanthal-3 includes $5.7 \mathrm{M}(35 \%)$ and $10.4 \mathrm{M}(65 \%)$ simple and heterozygous single nucleotide polymorphisms (SNPs), and about $90 \%$ of all these polymorphisms are located in inter-genic regions.

\section{Conclusion}

The whole-genome sequence of $A$. heterophyllus $\mathrm{cv}$. BARI Kanthal-3 reveals extremely high single nucleotide polymorphisms in inter-genic regions. The findings of this study will help better understanding the evolution, domestication, phylogenetic relationships, year-round fruiting and the markers development for molecular breeding of this highly nutritious fruit crop.

\section{Background}

The genus Artocarpus (family, Moraceae) comprises approximately 70 species of food-producing plants that are extended throughout the tropical and subtropical regions of the world [1, 2]. Among them, jackfruit, $A$. heterophyllus Lam. is a tropical evergreen tree, which produces the largest edible single fruit in the world (up to $50 \mathrm{~kg} /$ fruit) $[3,4]$. The place of origin of this fruit tree is still unclear, but it is predicted 
to be indigenous to the rainforests of the Western Ghats of India. It is widely cultivated throughout the tropical lowlands in South and Southeast Asia, parts of central and eastern Africa, and Brazil [5-7]. Bangladesh is one of the highest jackfruit producing countries in the world. The jackfruit popularly known as Kanthal is the national fruit of Bangladesh. Its demand is increasing gradually due to its low price, high nutritious value, diversified uses and potentials for commercial cultivation and processing industry [7]. The jackfruit is commonly referred to as "poor man's food" due to its lower market price as well as high abundance in the summer season $[5,8]$. It is grown all over the Bangladesh, especially profusely in the central terrace ecosystem [9].

Bangladesh is one of the largest producers of jackfruits and accounts for about $21 \%$ of total fruit production of the country, which is only next to Mango as the principal fruit crop. During 2019-20, Bangladesh produced 1.1 million tons of jackfruit covering 16,592 hectares area [10]. Despite the numerous advantages, jackfruit tree is not commercially grown as a crop because of an extremely high variation in fruit quality, which is due to its cross-pollinated nature, seed-mediated propagation, short seasonal fruiting and susceptibility to abiotic stresses [7]. Therefore, the potential of this unique nutritious fruit crop has not yet been utilized in Bangladesh for ensuring food and nutritional security through commercial cultivation and industrial processing. Genetic improvement of the existing germplasms to overcome these problems will accelerate jackfruit to becoming a commercial crop in Bangladesh [11]. Although several studies have described the high diversity of jackfruit in Bangladesh but none of them are systematic and comprehensive $[12,13]$. The underlying molecular mechanisms of the trait diversity in jackfruit is largely unknown. The harvesting period of jackfruit is short (June-August) resulting in a large wastage of this fruit amounting $20-30 \%$ of the crop or even more during the season. Bangladesh Agricultural Research Institute (BARI) developed a year-round jackfruit variety namely, BARI Kanthal-3 in 2014. Number of fruits per plant per year ranges between 219-245, fruits are medium in size (averaging $5.43 \mathrm{~kg}$ each) and yield is $1165-1504.2 \mathrm{~kg}$ fruit/plant (Figure 1). The ripened edible potion contains $35.06 \mathrm{mg} / \mathrm{g}$ ß- carotene and $23.6 \%$ of total soluble sugar (TSS) [1].

Whole genome sequencing provides complete coverage of the coding and noncoding regions of the genome [14], which allows a more comprehensive assessment of the genome of any organism including those of plants [15]. It provides the genetic foundation that enables a greater efficiency to manipulate genetic diversity at key genes and enhance, reduce or add certain features to a plant phenotype [15]. Since the first whole genome sequencing of the model plant, Arabidopsis thaliana in 2000, a large number of plants from diverse taxonomic groups have been sequenced, and genes responsible for various plant traits have been characterized and cloned [15-17]. Recently, whole genome sequencing of economically important plants such as jute, Corchorus spp. [18], hilsa, Tenualosa ilisha [19], and goat, Capra hircus [20] have created huge public interest in Bangladesh. Recent advances in genomics analyses have revealed large numbers of single nucleotide polymorphisms (SNPs) as the most common form of DNA sequence variation between alleles in several plant species [21]. Because of their high abundance, significant information content, when associated with genes, SNPs have gained the center stage as the principal markers of choice for molecular genetics studies. This includes their application in shortening the time of breeding new varieties in many crops through using marker assisted selection [21, 
22]. SNPs have also been applied for several years to assess diversity in specific genes or genomic regions, revealing the phylogenetic relationships between species. However, the emergence of high throughput sequencing technologies allows the SNP-based genetic diversity studies to be carried out at scale and can be useful in conserving diversity in domesticated populations. Plant phylogenetic and evolutionary studies are conventionally based on variation that exist at genes, and hence the knowledge of SNPs in these regions is essential for this analysis [23]. It is also important to know the location of SNPs in the whole genome, because if a SNP is present in the coding or regulatory region of a gene, it can greatly affect the functional activity of the resulting protein, such as an enzyme in a biosynthetic pathway [24] by affecting gene expression and transcriptional and translational promoter activities. Therefore, SNPs can often be responsible for phenotypic variations that exits between individuals and be utilized as selectable genetic markers for improving agronomic traits. However, large scale genomic studies for the identification of SNPs in the jackfruit genome are still not available.

Jackfruit is a highly priority fruit plant in Bangladesh as the National Agricultural Research System (NARS) has recently placed a focus on improving fruiting characteristics of this species and supporting its commercial development. Until now, only a limited amount of genomic information has been made available for the genus of $A$. heterophyllus $[5,25]$. Although the development of a year-round fruiting variety BARI Kanthal-3 offers an opportunity for commercial cultivation and processing of the jackfruit, nothing is known about the underlying molecular mechanism of its year-round fruiting characteristics and other beneficial traits. Therefore, the whole genome sequencing of $A$. heterophyllus cv. BARI Kanthal3 and decoding its genome could offer a potentially significant improvement of jackfruit for desired traits through molecular breeding. Molecular understanding of the extremely high phenotypic variabilities in jackfruit would facilitate the future development of high yielding, year-round fruiting, biotic and abiotic stress (e.g., flood, saline, drought and pest) tolerant jackfruit varieties through molecular breeding, which is essential for establishing jackfruit-based processing industry in Bangladesh and elsewhere. Therefore, we report here a draft annotated whole genome assembly of the year-round fruiting $A$. heterophyllus $\mathrm{cv}$. BARI Kanthal-3 for first time. The results of the promising phenotypic characteristics of the BARI Kanthal3 variety, together with both the de novo and reference-guided assemblies, and the identified SNPs, sheds light on the genetic variation that exists within the A. heterophyllus genome.

\section{Results And Discussion}

\section{Source and phenotypic features of the BARI Kanthal-3 variety}

To develop the variety of BARI Kanthal-3, germplasm was collected from all over the country including Chittagong Hiltracts such as Ramgarh of Khagrachari of Bangladesh. In 2014, an accession was certified for cultivation in Bangladesh with a varietal name of BARI Kanthal-3, representing a new and unique variety of jackfruit in Bangladesh that bear fruits for almost all of the calendar year (September to June). It is a high yielding variety with an average of 232 (range 219-245) fruits per plant yielding $1165-1504.2$ $\mathrm{kg}$ fruit/plant/year (Fig. 1). The fruits of BARI Kanthal-3 were medium (average $5.43 \mathrm{~kg}$ each) and average yield was $133.2 \mathrm{t} / \mathrm{ha}$ /year (Fig. 1). This variety was not affected by any sort of infectious 
pathogens or pests (data not shown). The plant is erect and medium bushy. The pulp of the fruit is medium soft, slightly yellow, medium juicy, highly sweet and aromatic. The amounts of $ß$ - carotene and total soluble solid (TSS) in fruits were $35.06 \mathrm{mg} / \mathrm{g}$ and $23.6 \%$, respectively. The edible portion of the fruit was $52.5 \%$ (Table 1) [1]. A large body of literature revealed that jackfruit is a rich source of carbohydrates, minerals, carboxylic acids, dietary fiber, vitamins and minerals and bioactive compounds $[1,26]$. Considering the yield, year-round fruiting and nutritional quality of the fruits, the BARI Kanthal-3 could be utilized as a genetic resource for breeding of jackfruit for commercial cultivation in Bangladesh and elsewhere. To understand the underlying molecular mechanisms of unique traits of this new variety, genome sequencing and analysis of genomic data are needed.

Table 1 Tree and fruit characteristics of Artocarpus heterophyllus cv. BARI Kanthal-3

\begin{tabular}{ll} 
Parameters & Features/traits \\
\hline Average No. of fruits/plant & 232 \\
\hline Average fruit yield/year & $133.2(\mathrm{t} / \mathrm{ha})$ \\
\hline Average fruit weight $(\mathrm{kg})$ & $5.43 \mathrm{Kg}$ \\
\hline Harvesting period & Sep-June \\
\hline Edible portion & $52.5 \%$ \\
\hline $\mathrm{pH}$ & 5.21 \\
\hline TSS & $23.6{ }^{\circ} \mathrm{Brix}$ \\
\hline Vitamin C & $2.0 \mathrm{mg} / 100 \mathrm{~g}$ \\
\hline Total sugar & $21.74 \%$ \\
\hline Reducing sugar & $6.02 \%$ \\
\hline Non-reducing sugar & $15.72 \%$ \\
\hline Moisture content & $69.10 \%$ \\
\hline Dry matter & $30.90 \%$
\end{tabular}

\section{Genome sequencing and assembly}

A total of 655,819 raw Illumina pair-end sequencing reads from the extracted DNA of $A$. heterophyllus cv. BARI Kanthal-3 leaf tissues were generated. The genome size of BARI Kanthal-3 was estimated to be 1.04 Gb with a heterozygosity rate of $1.62 \%$ based on K-mer analysis of the short read data (Fig. 2). The estimated size is similar to the recently reported $1.01 \mathrm{~Gb}$ genome size of $A$. heterophyllus [5], and is consistent with the c-value of $1.20 \mathrm{pg}$ [27]. The BARI Kanthal-3 has a higher heterozygosity rate compared 
to the only one available reference genome of a seasonal jackfruit from India recently published by Sahu et al. [5].

After quality filtering of the short reads using Trimmomatic, 218,562 clean reads were obtained (Table 2). The high-quality reads assembled into different contigs using SOAPdenovo2, which ultimately yielded a base assembly of $1.36 \mathrm{M}$ scaffolds, totaling $843 \mathrm{Mb}$. The N50s of scaffolds were $1.8 \mathrm{~Kb}$ (Table 2). In a recent study from India, the genome of the $A$. heterophyllus with high-quality reads was assembled into 108,267 scaffolds, totaling $982 \mathrm{Mb}$ [5]. The BARI-Kanthal-3 contigs were then scaffolded together using the reference guided approach using the existing published draft reference genome of jackfruit [5] and the software RAGTAG, and finally gaps in the scaffolds were filled using the same pair-end Illumina data and Gapcloser software. In this case, SOAPdenovo2 + RAGTAG + GapCloser produced a base assembly of N50 size $=425 \mathrm{~Kb}$ in 218,562 scaffolds (Table 2). The GC content of BARI Kanthal-3 was $34.10 \%$ which is comparable to the GC content of a seasonal $A$. heterophyllus from Indian origin that was recorded as $32.9 \%[5]$.

Table 2 Result of de novo and reference guided genome assembly of Artocarpus heterophyllus cv. BARI Kanthal-3

\begin{tabular}{|lccccccc|}
\hline Assembly & $\begin{array}{l}\text { N50 } \\
\text { number }\end{array}$ & $\begin{array}{l}\text { N50 } \\
\text { size } \\
(\mathrm{Kb})\end{array}$ & $\begin{array}{l}\text { N90 } \\
\text { number }\end{array}$ & $\begin{array}{l}\text { N90 } \\
\text { size } \\
(\mathrm{Kb})\end{array}$ & $\begin{array}{l}\text { Longest } \\
\text { Sequence } \\
(\mathrm{Kb})\end{array}$ & $\begin{array}{l}\text { Num } \\
\text { Sequence }\end{array}$ & $\begin{array}{l}\text { Total } \\
\text { Bases } \\
(\mathrm{Mb})\end{array}$ \\
\hline SOAPdenov02 & 88,402 & 1.8 & 720,032 & 0.2 & 65 & $1,364,052$ & 817.7 \\
$\begin{array}{l}\text { SOAPdenovo2+ } \\
\text { RAGTAG + Gapcloser }\end{array}$ & 561 & 425 & 14,076 & 1.4 & 2,611 & 218,562 & 843 \\
\hline
\end{tabular}

\section{Genome assembly validation}

Scaffolds from the BARI Kanthal-3 assembly were compared against the reference genome using the nucmer software and showed a high degree of conservation; output for a comparison of the BARI Kanthal-3 scaffolds against the largest scaffold in the reference genome is represented in Fig. 3. This is just one portion of the genome (approx. 3.5Mb) that is represented but we found the same degree of high similarity across the rest of the genome.

To assess the representation of a complete conserved core gene set in the BARI Kanthal-3, assembly an analysis was carried out to assess the quality and completeness of the draft genome using the Benchmarking Universal Single-Copy Orthologs (BUSCO) datasets and an orthologue data base (Fig. 4). 
We identified 1,614 single copy orthologs (SCOs). Among these SCOs, 97.21\% (1569/1614) were complete nucleotide (single copy $=1094$ nucleotides and

duplicated $=475$ nucleotides), whereas 21 and 24 nucleotides were fragmented and missing, respectively (Figure 3). Our present findings aligned with the recently reported findings of Sahu et al., who reported that out of 1440 BUSCO ortholog groups searched in the A. heterophyllus assembly, 95\% (1369/1440) were complete BUSCOs, 932 (64.7\%) were "complete single-copy", 437 (30.3\%) were "complete duplicated", and 15 (1\%) were "fragmented", and 56 (4\%) were "missing" [5].

We also identified SCOs from the genomes of other four species (A. heterophyllus, A. altilis, M. notabilis, A. thaliana), and compared those with BARI-Kanthal-3 genome. In this study, 706 SCOs that were found to be shared across the genomes of five species (Fig. 5A). Remarkably, none of the SCOs were found to be unique for BARI Kanthal-3 genome. Phylogenetic analysis was performed using the 706 shared SCOs following the neighbor-joining method with 100 bootstraps (Fig. 5B). The phylogenetic analysis showed that two genomes of $A$. heterophylus (BARI Kanthal-3 and $A$. heterophyllus) clustered more closely related to other three genomes. Therefore, $A$. heterophyllus is the closest to the BARI Kantal-3 while $A$. thaliana branched more distantly from BARI Kantal-3 in the tree (Fig. 5B).

\section{Variant analysis}

The processed WGS reads were aligned against the A. heterophyllus draft assembly. Out of a total of 439 $M$ reads, $417 \mathrm{M}(95.1 \%)$ were found to be aligned in exact pairs. A total of 16 million single-nucleotide polymorphisms (SNPs) were called from the dataset including $5.7 \mathrm{M}(35.0 \%)$ simple and $10.4 \mathrm{M}(65.0 \%)$ heterozygous SNPs (Table 3 and Fig. S1). Approximately, $90 \%$ of all polymorphisms are located in intergenic regions. In this study, 144,787 (2.5\%) and 426,997 (7.5\%) of the simple SNPs, and 250,715 $(2.4 \%)$ and $739,288(7.1 \%)$ of the heterozygous SNPs, were found in the exons and introns, respectively (Table 3). We further predicted the effects of variants on genes. As expected large fraction of the variants were in the intergenic (64.5\%), intronic (5\%) and up/down-stream regions (29\%) of the genes (Fig. 6A). There are 232,587 missense mutations and 4,750 gained stop codons suggesting an altered protein function in BARI Kanthal-3 (Fig. 6B). One of the important findings from this study is the high level of heterozygosity in the year-round fruiting jackfruit genome. The high level of heterozygosity in $A$. heterophyllus genome raises the question of which allele, for each heterozygous locus, is represented by the reference genome (Table 4). Therefore, the inherent differences between individual plants should always be considered when utilizing the reference genome to detect SNP variants [28].

Table 3 Results of variant analysis of Artocarpus heterophyllus cv. BARI Kanthal-3 


\begin{tabular}{|lll|}
\hline Genomic region & Simple SNPs & Heterozygous SNPs \\
\hline Exonic & 144,787 & 250,715 \\
\hline Intronic & 426,997 & 739,288 \\
\hline Inter-genic & $5,111,742$ & $9,369,507$ \\
\hline Total & $5,683,526$ & $10,359,510$ \\
\hline
\end{tabular}

Table 4 Comparison between the previously reported Artocarpus heterophyllus sequence and BARI Kanthal-3 sequence

\begin{tabular}{|c|c|c|}
\hline Parameters & $\begin{array}{l}\text { Previously reported } A \text {. } \\
\text { heterophyllus sequence }\end{array}$ & BARI Kanthal-3 sequence \\
\hline $\begin{array}{l}\text { 1. No. of } \\
\text { scaffolds }\end{array}$ & 1. M scaffolds totaling $982 \mathrm{Mb}$ & 218,562 scaffolds totaling $843 \mathrm{Mb}$ \\
\hline $\begin{array}{l}\text { 2. Size of } \\
\text { N50s in the } \\
\text { scaffolds }\end{array}$ & $548 \mathrm{~kb}$ with the longest being $3.1 \mathrm{Mb}$ & $425 \mathrm{~kb}$ and with the longest being $2.6 \mathrm{Mb}$ \\
\hline $\begin{array}{l}\text { 3. GC } \\
\text { content (\%) }\end{array}$ & $32.9 \%$ & $34.10 \%$. \\
\hline $\begin{array}{l}\text { 4. BUSCO } \\
\text { results }\end{array}$ & $\begin{array}{l}1369(95 \%) \text { complete BUSCOs where } \\
932(64.7 \%) \text { BUSCO genes were } \\
\text { "complete single-copy", } 437 \text { (30.3\%) } \\
\text { were "complete duplicated", } 15(1 \%) \\
\text { were "fragmented", and } 56 \text { (4\%) were } \\
\text { "missing" }\end{array}$ & $\begin{array}{l}1569(97.2 \%) \text { were complete BUSCOs in } \\
\text { which } 1094(67.8 \%) \text { BUSCO genes were } \\
\text { "complete single-copy", } 475(29.4 \%) \text { were } \\
\text { "complete duplicated", } 21(1.3 \%) \text { were } \\
\text { "fragmented", and } 24 \text { (1.5\%) were } \\
\text { "missing" }\end{array}$ \\
\hline $\begin{array}{l}\text { 5. Genome } \\
\text { size }\end{array}$ & $\begin{array}{l}\text { The estimated genome size was } 1.01 \\
\text { Gbp }\end{array}$ & The estimated genome size was $1.04 \mathrm{Gbp}$ \\
\hline
\end{tabular}

SNPs have been indicated as the major factors in the creation of phenotypic variation and their effect on functional changes of genes is used as a tool in functional genomics of organisms [29]. The discovery and identification of genomic variants such as SNPs, together with the determination of their location in the genome, can provide valuable information for breeding programs. In plants, many traits of interest have been linked with SNPs $[22,30,31]$. SNPs have been reported to play a role in metabolism, cellular processes and signaling, that could be addressed in detail at the breeding level. This study for the first time identified the SNPs in the genome of a year-round fruiting jackfruit cultivar, which promises the development of genetic markers associated with the important traits of this economically important plants including the genes regulating flowering and fruit development. The availability of SNPs within the 
coding and regulatory sequences also offers the prospect of identifying the causative variations influencing these processes [32].

One of the hallmark findings of this study is that majority of the SNPs $(47.29 \%)$ of BARI Kantha-3 were localized in the intergenic regions. The SNPs occur more frequently in the proximity of genes.

Approximately, 25\% of the intergenic SNPs were detected within the region spanning $10 \mathrm{~kb}$ upstream of the gene start site and $10 \mathrm{~kb}$ downstream of the gene end site [33], implying the possibility that some of these SNPs affect the expression of the nearest neighboring genes. The SNP markers have become extremely popular in plant molecular genetics due to their genome-wide abundance and amenability for high to ultra-high-throughput detection platforms. For example, SNPs are reported to be regulating various Quantitative Trait Loci (QTL) responsible for cold and disease resistance such as such as blight, bacterial canker and gray mold [34,35]. Novel SNPs associated with flowering in Raphanus sativus inbred lines for marker-assisted backcross breeding has recently been discovered by transcriptome sequencing and computational analysis [36]. Therefore, a further transcriptomics study is needed for the identification of genes associated with flowering and year-round fruiting of BARI Kanthal-3. In this study, most of the SNPs were identified in inter-genic regions (including intergenic regions, 5' UTR, 3' UTR, and introns) rather than in the coding regions. It has been reported that high frequency of genetic variants in the noncoding regions likely results from less selection pressure from natural selection and/or domestication [39]. However, DNA polymorphisms in these regions have been reported to play important roles during evolution and domestication. For example, a mutation in the 5 ' regulatory region of the $q S H 1$ gene, an ortholog of the Arabidopsis homeobox gene REPLUMLESS (RPL) results in the absence of abscission zone formation and thus loss of seed shattering in a subset of temperate japonica cultivar of rice [40]. Similarly, a considerable number of mutations in introns in pre-harvest sprouting (PHS) genes lead to PHS in rice plant (Reference). Among the 12 PHS mutants (phs), mutations in genes encoding major enzymes of the carotenoid biosynthesis pathway, causes photo-oxidation and ABA-deficiency phenotypes, of which the latter is a major factor controlling the PHS trait in rice (Reference). Interestingly, in jackfruit, MADS-box genes and carotenoid biosynthesis genes, were the primary targets for domestication [25]. However, the role of inter-genic SNPs in A. heterophylus in domestication of this horticultural plant needs to be explored further.

This study for the first-time reports about the distribution of SNPs in a year-round fruiting cultivar of $A$. heterophyllus $\mathrm{cv}$. BARI Kanthal-3. The identified SNPs in this study can be used to identify new functional genes and their regulatory activities specific to BARI Kanthal-3. The identified SNPs can also be used as markers to characterize cultivars and wild relatives of $A$. heterophyllus. Furthermore, the whole genome sequence data and the identified SNPs of a new year-round fruiting jackfruit cultivar of Bangladesh could facilitate further genomics and post-genomics studies for detecting other trait-specific genes that are essential for molecular breeding of jackfruit.

\section{Conclusions}


This study analyzed the phenotypic properties and whole genome sequence data of a new year-round fruiting variety of jackfruit BARI Kanthal-3. The fruit quality, yield and year-round fruiting properties of the BARI Kanthal-3 indicate it as a unique genetic material for the improvement of jackfruit for commercial cultivation and development of jackfruit-based processing industry. The de novo genome assembly through SOAPdenovo2 produced a base assembly of $\mathrm{N} 50$ size $=1.8 \mathrm{~Kb}$ in $1.36 \mathrm{M}$ scaffolds totaling 817.7 $\mathrm{Mb}$. During reference-guided assembly, SOAPdenovo2 + RAGTAG + Gapcloser produced a base assembly of $\mathrm{N} 50$ size $=425 \mathrm{~Kb}$ in 218,562 scaffolds. A total of $843 \mathrm{Mb}$ of the BARI Kanthal-3 genome was scaffolded. The comparison of scaffolds from the BARI Kanthal-3 assembly against the reference genome using the nucmer software showed a high degree of conservation. The phylogenetic analysis of the shared SCOs showed that A. heterophyllus is the closest species of the BARI Kanthal-3. The estimated genome size and the heterozygocity of BARI Kanthal-3 were $1.04 \mathrm{Gbp}$ and $1.62 \%$, respectively. Out of 16 million single-nucleotide polymorphisms (SNPs) detected in BARI Kanthal-3 genome, 5.7M (35\%) and $10.4 \mathrm{M}(65 \%)$ were simple and heterozygous SNPs, respectively. Remarkably, approximately, $90 \%$ of all polymorphisms were located in the inter-genic regions. This study for the first time sequenced the whole genome of a year-round fruiting jackfruit variety BARI Kanthal-3. The genomic data generated, and associated SCOs and SNPs identified in this research would be useful for characterization of trait-specific genes and development of markers for molecular breeding for the improvement of jackfruit. The development of a high yielding year-round fruiting variety of jackfruit with high nutritional quality of fruits would facilitate the commercialization of this underutilized fruit crop for ensuring food and nutritional security of the ever-increasing population of Bangladesh and other tropical countries.

\section{Materials And Methods}

\section{Collection of phenotypic data and samples}

The mean values $(\mathrm{n}=5)$ of the phenotypic and biochemical data of Artocarpus heterophyllus (BARI Kanthal-3) were obtained from the naturally grown and cultivated plants of BARI Kanthal-3 variety using the standard protocols.

\section{Collection of leaf samples, genomic DNA extraction, WGS library construction, and sequencing}

The young jackfruit cv. BARI Kanthal-3 leaf samples were collected from the grafted seedlings cultivated at Horticulture Center of Bangladesh Agricultural Research Institute (BARI), Joydebpur, Bangladesh. The samples were identified as jackfruit by Professor Md. Abdul Baset Mia of Department of Crop Botany of Bangabandhu Sheikh Mujibur Rahman Agricultural University (BSMRAU) in Bangladesh. A voucher specimen was deposited in the herbarium of the Department of Crop Botany of BSMRAU with a specimen No. CBT-BSMRAU-00035.

Genomic DNA was extracted from freshly harvested leaves of BARI Kanthal-3 using the QIAGEN DNeasy Plant Mini Kit (QIAGEN, Valencia, California, USA) following the manufacturer's protocol. The quality of the DNA was visually inspected by $1 \%$ agarose gel electrophoresis. The quantity of the DNA was assessed by a Qubit Fluorometer (Invitrogen, Carlsbad, CA, USA) according to the manufacturer's 
instruction. Whole genome sequencing (WGS) library preparation was performed using Nextera XT DNA library preparation kit (Illumina Inc., San Diego, CA, USA) according to the manufacturer's protocol. Briefly, after normalization, DNA samples were fragmented and tagged by tagmentation in a single-tube reaction [41]. The tagmented DNA was amplified through a limited-cycle PCR program using a unique combination of barcode primers, the Index 1 (i7), Index 2 (i5) and full adapter sequences required for cluster generation. Amplification was followed by a cleanup step that purified the library DNA, and removed small library fragments by using Agencourt AMPure XP beads (Beckman Coulter, Inc.). Finally, prepared libraries were loaded onto a reagent cartridge, clustered on the NextSeq 550 System, and pairedend sequencing ( $2 \times 150$ bp) was performed using the Illumina NextSeq 550 High-Output Kit on the NextSeq 550 desktop sequencer.

\section{Retrieval of data from the GenBank}

In addition to the WGS data of BARI Kanthal-3, we also collected the genomic data (WGS) three related species of Artocarpus heterophyllus (family Moraceae) i.e., A. heterophyllus, A. altilis, Morus notabilis, and Arabidopsis thaliana from the AOCC ORCAE platform and the National Center for Biotechnology Information (NCBI) under GenBank accession numbers of CNGB CNP0000486 (https://bioinformatics.psb.ugent.be/orcae/aocc/overview/Arthe), CNGB CNP0000715 (https://bioinformatics.psb.ugent.be/orcae/aocc/overview/Artal), NCBI ASM41409v2 (https://www.ncbi.nlm.nih.gov/genome/?term=ASM41409v2) and NCBI TAIR10.1 (https://www.ncbi.nlm.nih.gov/genome/?term=TAIR10.1), respectively.

\section{De novo genome assembly}

The generated WGS data were filtered through Trimmomatic v0.38 [42] with option "LEADING:20 TRAILING:20 SLIDINGWINDOW:4:15 MINLEN:50" parameters to remove Illumina adapter, known Illumina artifacts, phiX, and low-quality regions. The processed reads were assembled by SOAPdenovo2 v2.04 [43] with k-mer=39 and subsequently scaffolded using a reference guided approach by RAGTAG [44] software with default parameters. GapCloser v1.12 [43] with default parameters ("-I 150 t 32 -p $31^{\prime \prime}$ ) was utilized for gap closing using the pair-end data.

\section{Genome assembly validation}

The scaffolded sequences were compared against the reference genome by nucmer v4.0.0rc1 [45] using the default parameters. The genome assembly completeness was assessed using BUSCO (Benchmarking Universal Single-Copy Orthologues), v4.1.4 [46] to evaluate the presence of conserved plant orthologs with the Embryophyta database 10 lineage. We predicted single copy orthologs (SCOs) from the genomes of four species (A. heterophyllus, $A$. altilis, M. notabilis, $A$. thaliana) along with the genome of BARI Kanthal-3. SCOs were predicted against the embryophyta orthologous database using BUSCO. Multiple sequence alignment of amino acid sequences for 706 SCOs was performed by MAFFT (multiple sequence alignment program) version 7 (https://mafft.cbrc.jp/alignment/software/), and the tree was visualized by Phylo.io (https://phylo.io/). 


\section{Genome size estimation}

The high-quality data ( 50X depth) were provided to Jellyfish v2.2.6 [47] with "-C -m 21 -s 5G -minquality $=25$ " parameters to generate $k$-mer $(K=21)$ frequency distribution. The output histograms were analyzed using GenomeScope [48] to estimate the genome size, heterozygosity level, error rates, and repeat fraction.

\section{Variant calling}

Processed Illumina data were aligned against the draft $A$. heterophyllus genome [5] using BurrowsWheeler Aligner (BWA) v 0.7.17 [49]. The aligned reads mapped with a quality score 30 or greater were analyzed by samtools/bcftools [50] to produce the raw variant calls. Simple single nucleotide polymorphisms (SNPS) were defined as SNPs with greater than $90 \%$ ALT allele frequency observed in at least 30 high quality reads (MAPQ>30). Following variant calling, we used snpEff to annotate variants and predict their effects on genes using a custom database generated using the $A$. heterophylus genome and annotation from https://bioinformatics.psb.ugent.be/gdb/aocc/arthe/ [5].

\section{Abbreviations}

BARI: Bangladesh Agricultural Research Institute; BUSCO: Benchmarking Universal Single-Copy Orthologs; BWA: Burrows-Wheeler Aligner; MAFFT: Multiple Alignment Using Fast Fourier Transform; SCOs: Single Copy Orthologues; SNPs: Single Nucleotide Polymorphisms; TSS: Total Soluble Sugar; QTL: Quantitative Trait Loci; WGS: Whole Genome Sequencing

\section{Declarations}

\section{Availability of data and materials}

The whole genome sequence data of the year-round fruiting jackfruit, $A$. heterophyllus $\mathrm{cv}$. BARI Kanthal-3 project have been deposited at GenBank under accession number JAIQDR000000000, and the assembly reports of the genome are also available at GenBank. The Illumina shotgun reads are available in the National Center for Biotechnology Information (NCBI) under BioProject accession number PRJNA686208. The version described in this paper is version JAIQDR000000000.1. The deposited plant leaf sample in the Department of Crop Botany of BSMRAU, Bangladesh could be accessible on request.

\section{Competing interests}

The authors declared that they have no competing interests.

\section{Funding}

This project was funded by the 'BSMRAU Physical Facility and Research Capacity Strengthening Project' under the Ministry of Education of the People's Republic of Bangladesh. Bioinformatics support and 
analysis was supported with funds from the Bangabandhu Research Chair in Food Security held by Dr. Sharpe at GIFS and supported by GIFS and the Bangladesh Agriculture Research Council.

\section{Authors' contributions}

All authors contributed intellectually to this study. TI conceived the study, designed the experiment, coordinated the project, provided reagents and laboratory support, interpreted the results, wrote and revised the manuscript. NA collected the plant samples, extracted DNA, and prepared the draft manuscript; $\mathrm{CK}$ assembled and annotated the sequenced data, interpreted results and wrote the manuscript; $\mathrm{MNH}$, interpreted the results, wrote and revised the manuscript; MJR, provided plant samples, collected and interpreted phenotypic and biochemical data and wrote manuscript; NUM and DRG, conducted experiments and prepared library for the DNA sequencing using Illumina Nextseq 550; AAN and $\mathrm{RI}$, analyzed sequenced data, prepared phylogenetic tree and wrote the manuscript; PKB, wrote and revised the manuscript; AGS, coordinated, wrote and revised the manuscript; All authors read, revised, edited and approved the final manuscript.

\section{Acknowledgements}

We are thankful to the 'BSMRAU Physical Facility and Research Capacity Strengthening Project' under the Ministry of Education of the People's Republic of Bangladesh for funding this research. The Global Institute for Food Security (GIFS), Canada and BDREN of UGC, Bangladesh also deserve our thanks for offering facilities for bioinformatics analyses of the genomic data of jackfruit cv. BARI Kanthal-3.

\section{Ethics approval and consent to participate}

Permission to collect leaf sample of Artocarpus heteropyllus Lam. was obtained.

\section{Consent for publication}

Not applicable.

\section{References}

1. Azad AK, Uddin M, Ohab MA, Sheikh MHR, Nag BL, Rahman MHH: Edited, Krishi Projukti Hatboi (Handbook on Agro-Technology), 9th edition, Bangladesh Agricultural Research Institute, Gazipur1701, Bangladesh, 2020.

2. Ranasinghe R, Maduwanthi S, Marapana R: Nutritional and health benefits of jackfruit (Artocarpus heterophyllus Lam.): A review. International journal of food science 2019, 2019.

3. Naik KC: South Indian fruits and their culture. South Indian fruits and their culture 1949.

4. Simmonds M, Preedy VR: Nutritional composition of fruit cultivars: Academic Press; 2015.

5. Sahu SK, Liu M, Yssel A, Kariba R, Muthemba S, Jiang S, Song B, Hendre PS, Muchugi A, Jamnadass R: Draft Genomes of two Artocarpus plants, Jackfruit (A. heterophyllus) and Breadfruit (A. altilis). 
Genes 2020, 11(1):27.

6. Rahman MA, Nahar N, Mian AJ, Mosihuzzaman M: Variation of carbohydrate composition of two forms of fruit from jack tree (Artocarpus heterophyllus L.) with maturity and climatic conditions. Food Chemistry 1999, 65(1):91-97.

7. Sidhu AS: Jackfruit Improvement in the Asia-Pacific Region: A Status Report: APAARI; 2012.

8. Rahman AM, Huq E, Mian A, Chesson A: Microscopic and chemical changes occurring during the ripening of two forms of jackfruit (Artocarpus heterophyllus L.). Food Chemistry 1995, 52(4):405410.

9. Miah MG, Islam MM, Rahman MA, Ahamed T, Islam MR, Jose S: Transformation of jackfruit (Artocarpus heterophyllus Lam.) orchard into multistory agroforestry increases system productivity. Agroforestry Systems 2018, 92(6):1687-1697.

10. Statistics. YoA: Bangladesh Bureau of Statistics (BBS), Statistics and Informatics Division (SID), Ministry of Planning, Government of the People's Republic of Bangladesh. In., vol. 32nd Series.; 2020.

11. Dhar M: Techniques of vegetative and in vitro propagation of jackfruit. Institute of Postgraduate Studies in Agriculture, Salna, Gazipur, Bangladesh 1998.

12. Hossain A: Status report on genetic resources of jackfruit in Bangladesh. International Plant Genetic Resources Institute Regional Office, Singapore 1996.

13. Saha M, Saha M, Rahman M, Nazrul M, Quasem A, Halder N, Hoque A: Variability in jackfruit. In: Proceedings of the Internal Research Review Workshop: 1996. 1-4.

14. Galperin MY, Koonin EV: From complete genome sequence to 'complete'understanding? Trends in biotechnology 2010, 28(8):398-406.

15. Chen F, Song Y, Li X, Chen J, Mo L, Zhang X, Lin Z, Zhang L: Genome sequences of horticultural plants: past, present, and future. Horticulture research 2019, 6(1):1-23.

16. Hübner S, Bercovich N, Todesco M, Mandel JR, Odenheimer J, Ziegler E, Lee JS, Baute GJ, Owens GL, Grassa CJ: Sunflower pan-genome analysis shows that hybridization altered gene content and disease resistance. Nature plants 2019, 5(1):54-62.

17. Gardner EM, Johnson MG, Ragone D, Wickett NJ, Zerega NJ: Low-coverage, whole-genome sequencing of Artocarpus camansi (Moraceae) for phylogenetic marker development and gene discovery. Applications in plant sciences 2016, 4(7):1600017.

18. Islam MS, Saito JA, Emdad EM, Ahmed B, Islam MM, Halim A, Hossen QMM, Hossain MZ, Ahmed R, Hossain MS: Comparative genomics of two jute species and insight into fibre biogenesis. Nature plants 2017, 3(2):1-7.

19. Das A, lanakiev P, Baten A, Nehleen R, Ehsan T, Ahmed O, Islam MR, Naser MN, Marma MS, Khan H: Genome of Tenualosa ilisha from the river Padma, Bangladesh. BMC Research Notes 2018, 11(1):13. 
20. Siddiki AZ, Baten A, Billah M, Alam MAU, Shawrob KSM, Saha S, Chowdhury M, Rahman AH, Stear M, Miah G: The genome of the Black Bengal goat (Capra hircus). BMC research notes 2019, 12(1):1-3.

21. Morgil H, Gercek YC, Tulum I: Single nucleotide polymorphisms (SNPs) in plant genetics and breeding. In: The Recent Topics in Genetic Polymorphisms. IntechOpen; 2020.

22. Mammadov J, Aggarwal R, Buyyarapu R, Kumpatla S: SNP markers and their impact on plant breeding. International journal of plant genomics 2012, 2012.

23. Lasky JR, Des Marais DL, McKAY JK, Richards JH, Juenger TE, Keitt TH: Characterizing genomic variation of Arabidopsis thaliana: the roles of geography and climate. Molecular Ecology 2012, 21(22):5512-5529.

24. Somerville C, Koornneef M: A fortunate choice: the history of Arabidopsis as a model plant. Nature Reviews Genetics 2002, 3(11):883-889.

25. Laricchia KM, Johnson MG, Ragone D, Williams EW, Zerega NJ, Wickett NJ: A transcriptome screen for positive selection in domesticated breadfruit and its wild relatives (Artocarpus spp.). American journal of botany 2018, 105(5):915-926.

26. Khan AU, Ema IJ, Faruk M, Tarapder SA, Khan AU, Noreen S, Adnan M: A Review on Importance of Artocarpus heterophyllus L.(Jackfruit). Journal of Multidisciplinary Applied Natural Science 2021.

27. Ohri D, Kumar A: Nuclear DNA amounts in some tropical hardwoods. Caryologia 1986, 39(3-4):303307.

28. Hawkins C, Caruana J, Schiksnis E, Liu Z: Genome-scale DNA variant analysis and functional validation of a SNP underlying yellow fruit color in wild strawberry. Scientific reports 2016, 6(1):111.

29. Hirakawa H, Shirasawa K, Ohyama A, Fukuoka H, Aoki K, Rothan C, Sato S, Isobe S, Tabata S: Genome-wide SNP genotyping to infer the effects on gene functions in tomato. DNA research 2013, 20(3):221-233.

30. Huq MA, Akter S, Nou IS, Kim HT, Jung YJ, Kang KK: Identification of functional SNPs in genes and their effects on plant phenotypes. Journal of Plant Biotechnology 2016, 43(1):1-11.

31. Zhang W, Mirlohi S, Li X, He Y: Identification of functional single-nucleotide polymorphisms affecting leaf hair number in Brassica rapa. Plant physiology 2018, 177(2):490-503.

32. Varshney RK: Gene-based marker systems in plants: high throughput approaches for marker discovery and genotyping. In: Molecular techniques in crop improvement. Springer; 2010: 119-142.

33. Yamamoto YY, Ichida H, Matsui M, Obokata J, Sakurai T, Satou M, Seki M, Shinozaki K, Abe T: Identification of plant promoter constituents by analysis of local distribution of short sequences. BMC genomics 2007, 8(1):1-23.

34. Zhang L, Lin G, Nino-Liu D, Foolad MR: Mapping QTLs conferring early blight (Alternaria solani) resistance in a Lycopersicon esculentum $\times$ L. hirsutum cross by selective genotyping. Molecular Breeding 2003, 12(1):3-19. 
35. Coaker G, Francis DM: Mapping, genetic effects, and epistatic interaction of two bacterial canker resistance QTLs from Lycopersicon hirsutum. Theoretical and Applied Genetics 2004, 108(6):10471055.

36. Kim J, Manivannan A, Kim D-S, Lee E-S, Lee H-E: Transcriptome sequencing assisted discovery and computational analysis of novel SNPs associated with flowering in Raphanus sativus in-bred lines for marker-assisted backcross breeding. Horticulture research 2019, 6(1):1-12.

37. Subudhi PK, Singh PK, DeLeon T, Parco A, Karan R, Biradar H, Cohn MA, Sasaki T: Mapping of seed shattering loci provides insights into origin of weedy rice and rice domestication. Journal of Heredity 2014, 105(2):276-287.

38. Sugimoto K, Takeuchi Y, Ebana K, Miyao A, Hirochika H, Hara N, Ishiyama K, Kobayashi M, Ban Y, Hattori T: Molecular cloning of Sdr4, a regulator involved in seed dormancy and domestication of rice. Proceedings of the National Academy of Sciences 2010, 107(13):5792-5797.

39. Barreiro LB, Laval G, Quach H, Patin E, Quintana-Murci L: Natural selection has driven population differentiation in modern humans. Nature genetics 2008, 40(3):340-345.

40. Konishi S, Izawa T, Lin SY, Ebana K, Fukuta Y, Sasaki T, Yano M: An SNP caused loss of seed shattering during rice domestication. Science 2006, 312(5778):1392-1396.

41. Hoque MN, Istiaq A, Clement RA, Sultana M, Crandall KA, Siddiki AZ, Hossain MA: Metagenomic deep sequencing reveals association of microbiome signature with functional biases in bovine mastitis. Scientific reports 2019, 9(1):1-14.

42. Bolger AM, Lohse M, Usadel B: Trimmomatic: a flexible trimmer for Illumina sequence data. Bioinformatics 2014, 30(15):2114-2120.

43. Luo R, Liu B, Xie Y, Li Z, Huang W, Yuan J, He G, Chen Y, Pan Q, Liu Y: SOAPdenovo2: an empirically improved memory-efficient short-read de novo assembler. Gigascience 2012, 1(1):2047-2217X2041-2018.

44. Alonge M, Soyk S, Ramakrishnan S, Wang X, Goodwin S, Sedlazeck FJ, Lippman ZB, Schatz MC: RaGOO: fast and accurate reference-guided scaffolding of draft genomes. Genome biology 2019, 20(1):1-17.

45. Kurtz S, Phillippy A, Delcher AL, Smoot M, Shumway M, Antonescu C, Salzberg SL: Versatile and open software for comparing large genomes. Genome biology 2004, 5(2):1-9.

46. Seppey M, Manni M, Zdobnov EM: BUSCO: assessing genome assembly and annotation completeness. Methods in molecular biology (Clifton, NJ) 2019, 1962:227-245.

47. Marçais G, Kingsford C: A fast, lock-free approach for efficient parallel counting of occurrences of $k$ mers. Bioinformatics 2011, 27(6):764-770.

48. Vurture GW, Sedlazeck FJ, Nattestad M, Underwood CJ, Fang H, Gurtowski J, Schatz MC: GenomeScope: fast reference-free genome profiling from short reads. Bioinformatics 2017, 33(14):2202-2204.

49. Li H, Durbin R: Fast and accurate short read alignment with Burrows-Wheeler transform. bioinformatics 2009, 25(14):1754-1760. 
50. Li H: A statistical framework for SNP calling, mutation discovery, association mapping and population genetical parameter estimation from sequencing data. Bioinformatics 2011, 27(21):2987-2993.

\section{Figures}
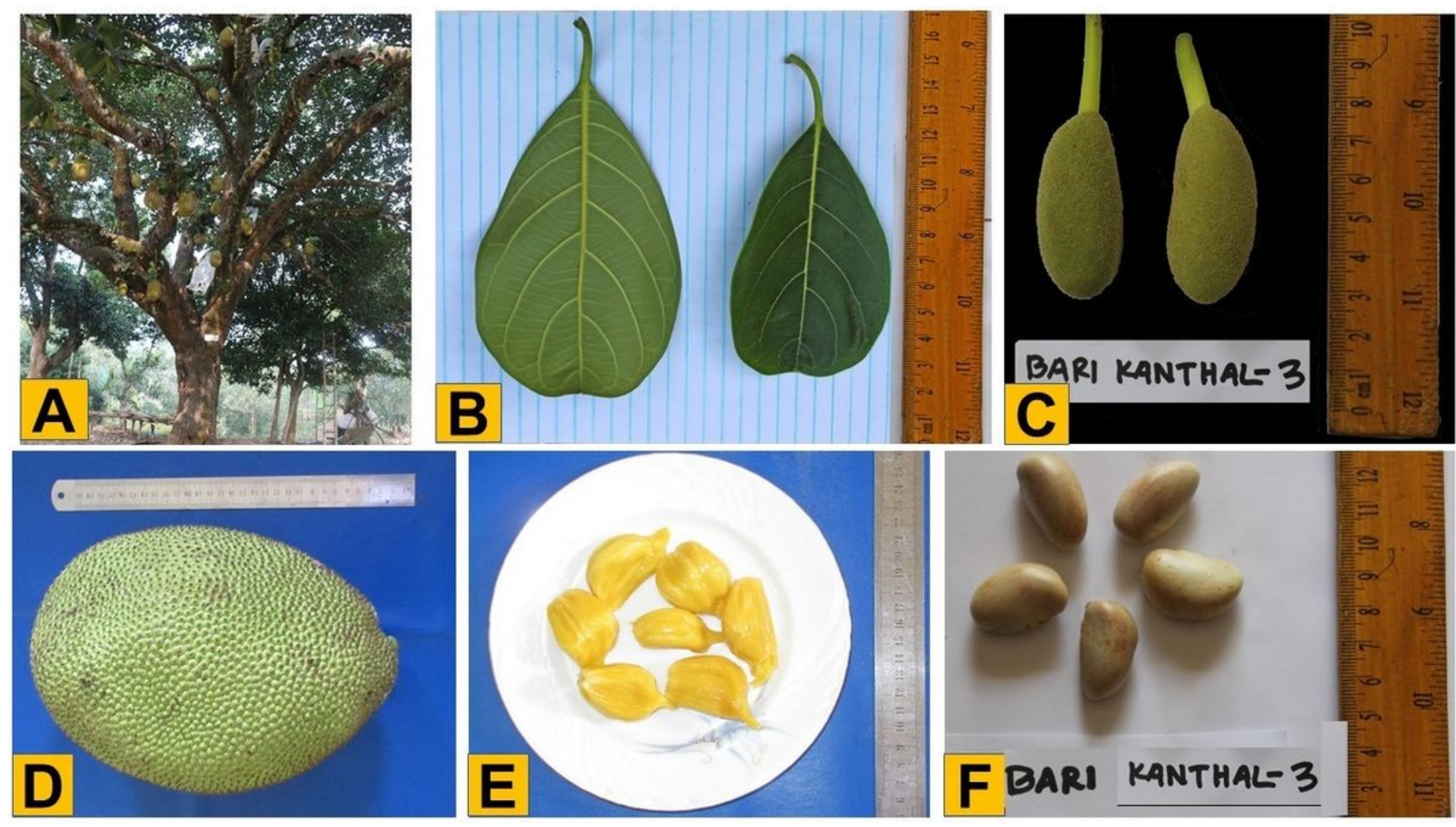

Figure 1

Phenotypic characteristics of BARI Kanthal-3. (A) Tree in situ, (B) Leaf, (C) Young fruits from the tree, (D) Mature fruit, (E) Kernel (flesh), and (F) Seed. 


\section{GenomeScope Profile}

len:1,035,793,220bp uniq:42.5\% het:1.62\% kcov:26.1 err:0.0262\% dup:2.29\% k:21

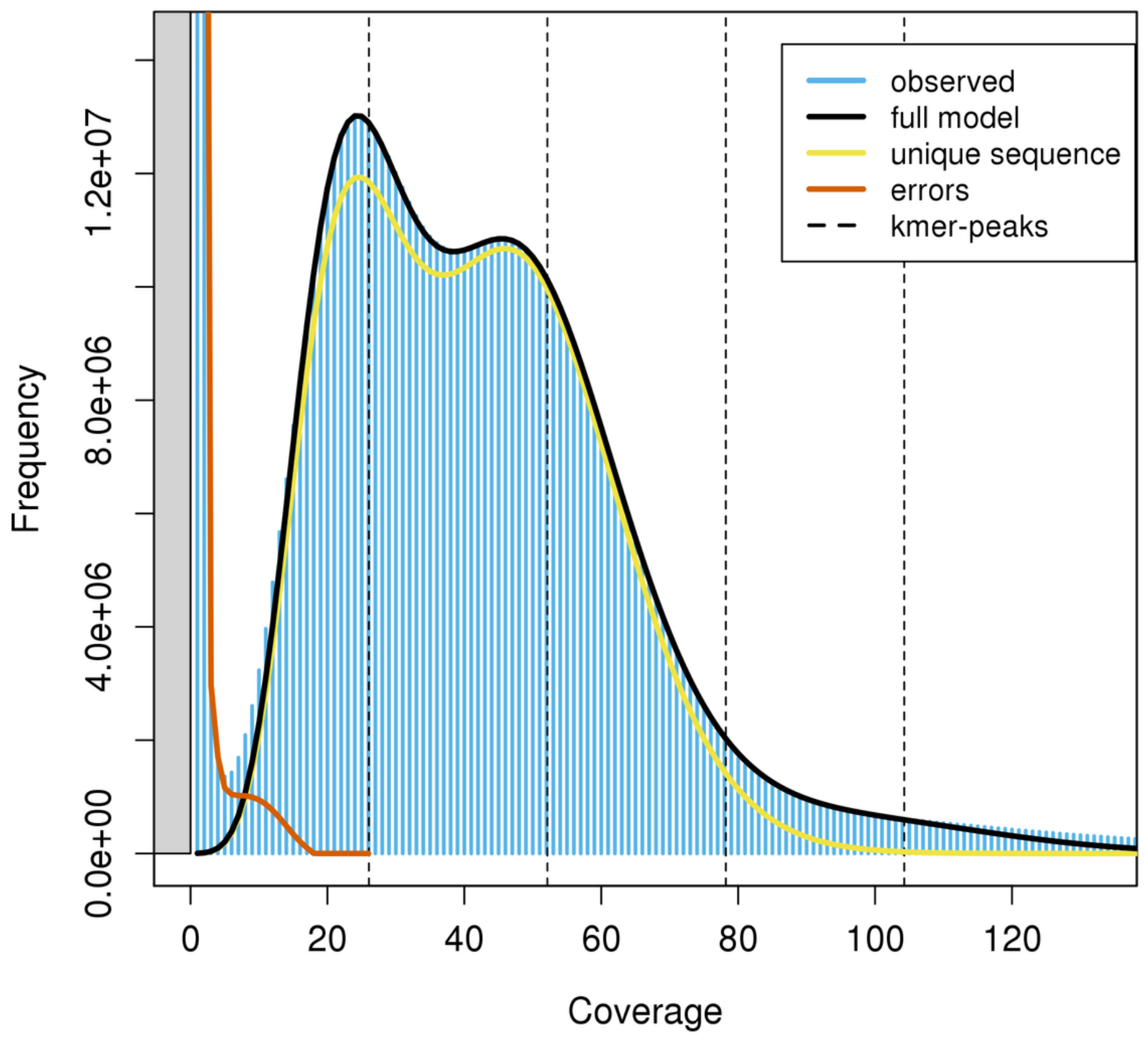

Figure 2

Genome size prediction of Artocarpus heterophyllus cv. BARI Kanthal-3. The X-axis represents the coverage of the genome while the $\mathrm{Y}$-axis represents the frequency levels. 


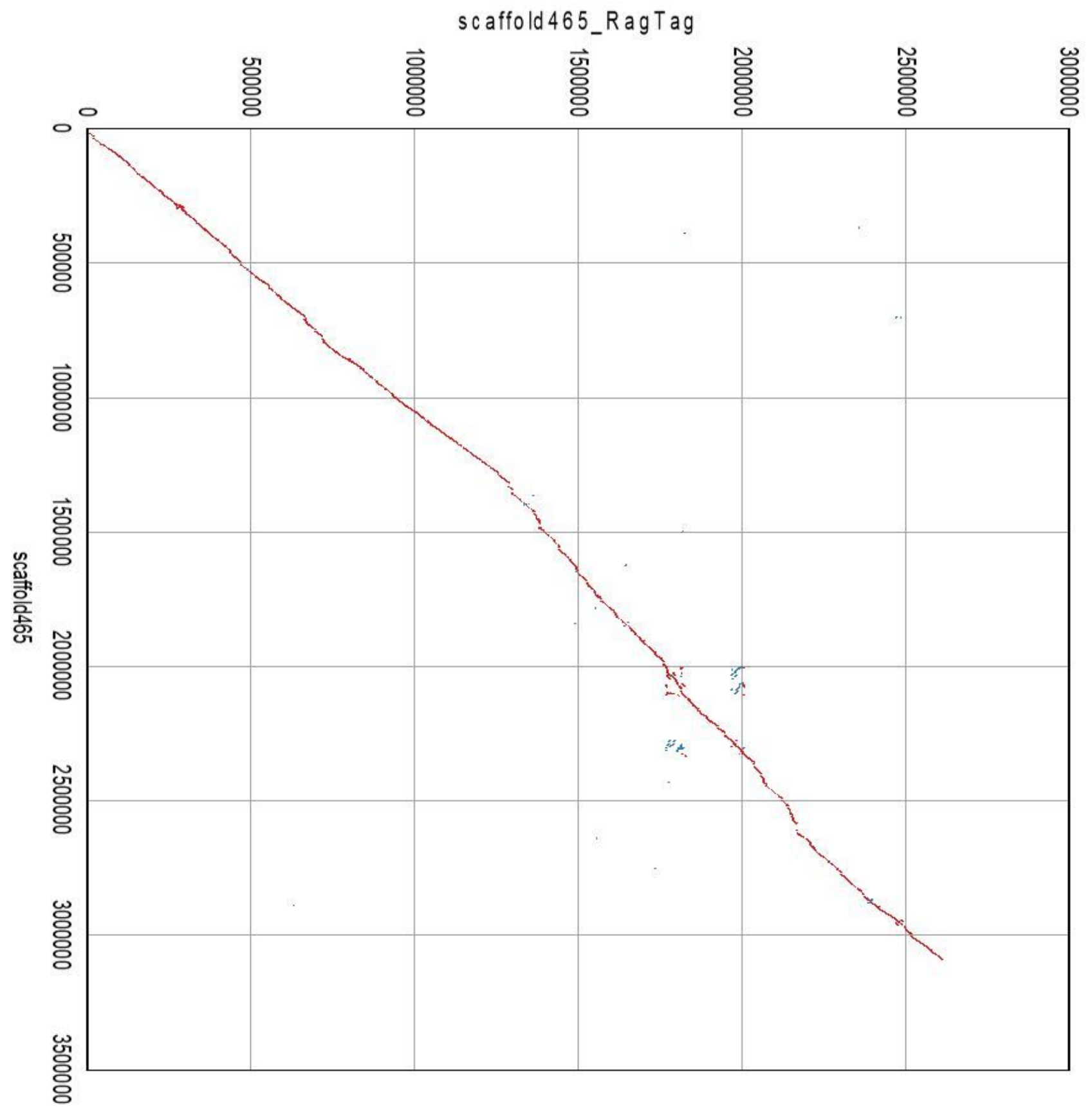

Figure 3

Comparison of the Artocarpus heterophyllus cv. BARI Kanthal-3 scaffolds against the largest scaffold in the reference genome. The $\mathrm{X}$ and $\mathrm{Y}$ axis represents the two genomes. 


\section{BUSCO Assessment Results}

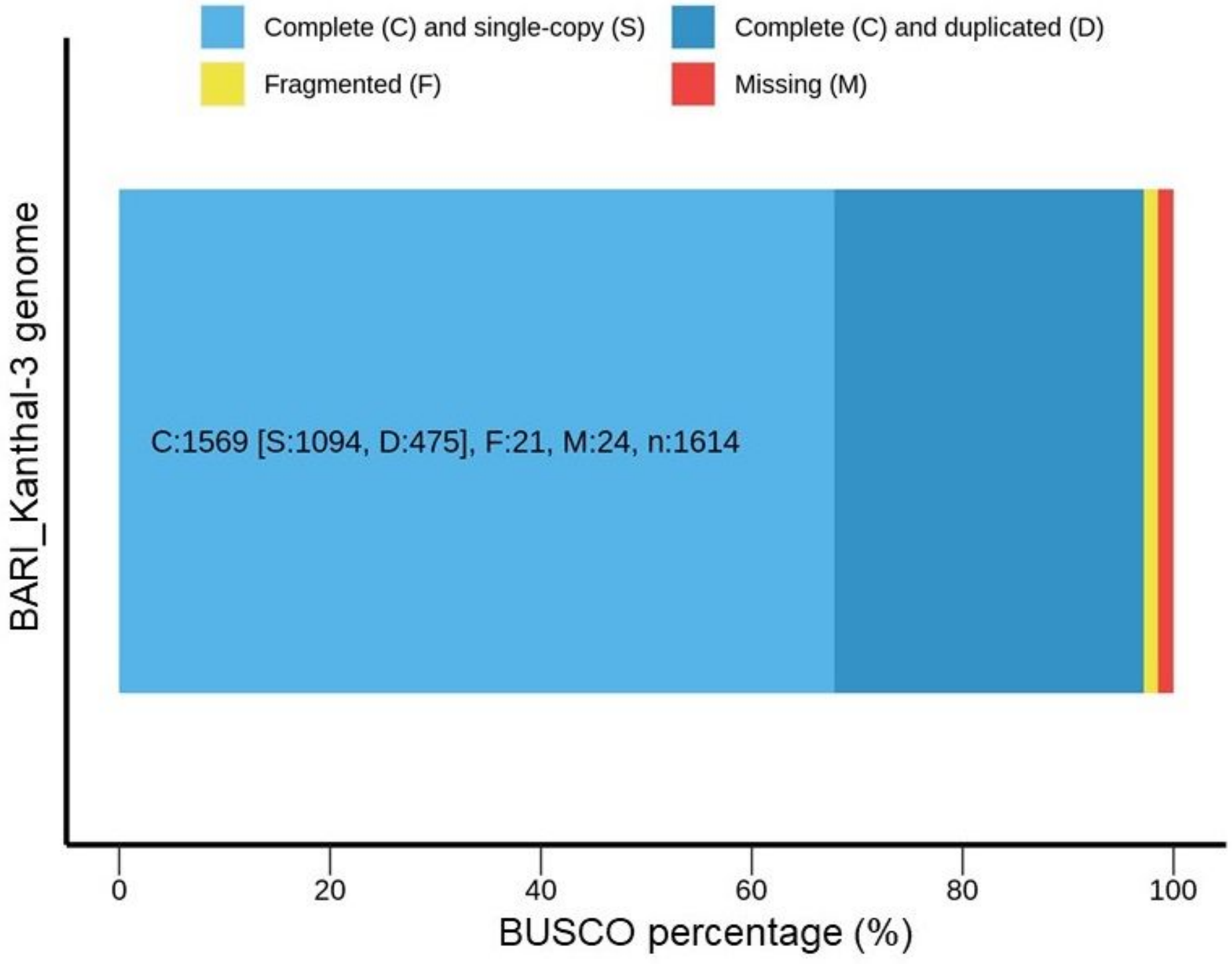

Figure 4

BUSCO (v.4.0.4) assessment results of BARI Kanthal-3. BUSCO completeness in Artocarpus heterophyllus cv. BARI Kanthal-3 is high indicating that the genome assemblies are of high gene space completeness. 

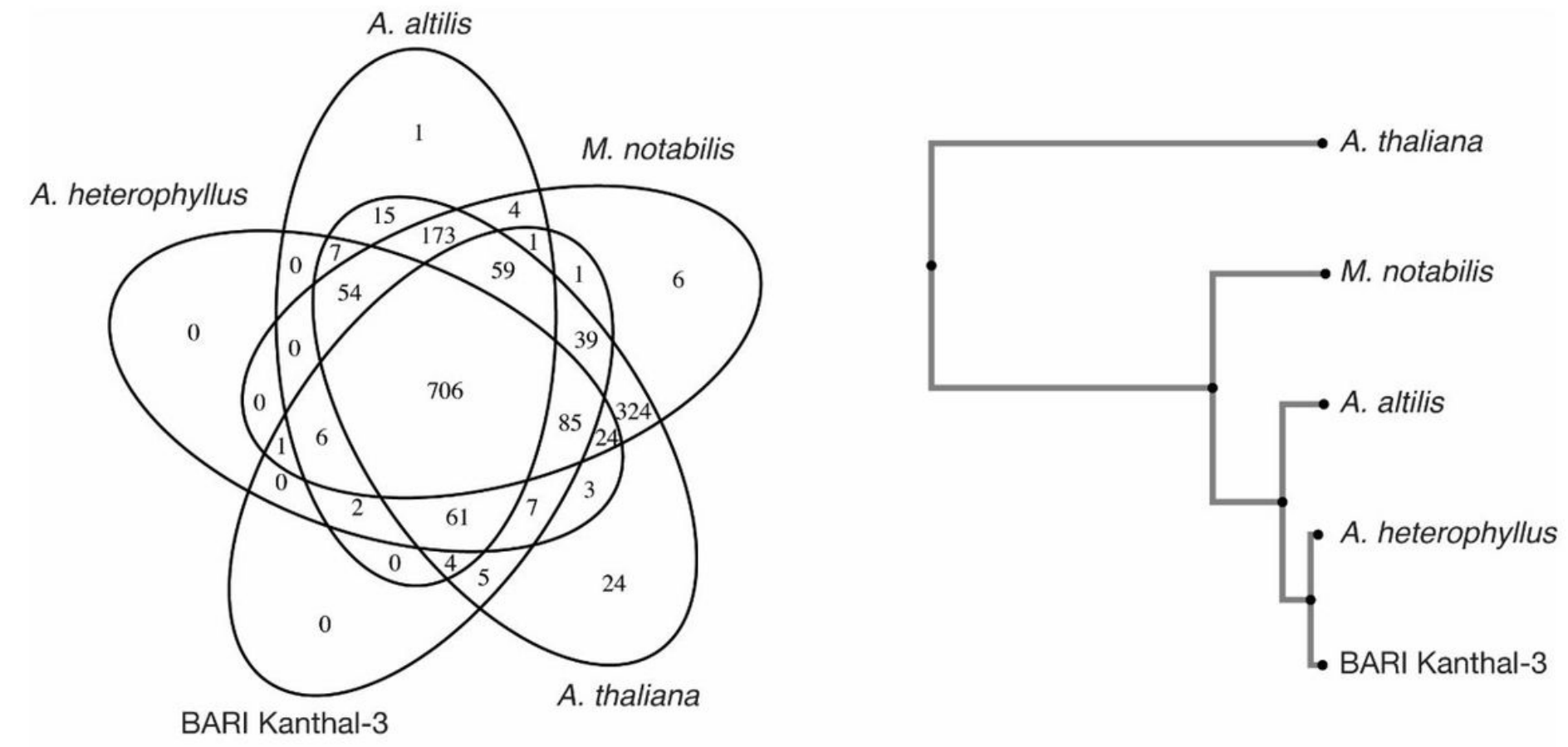

A

B

\section{Figure 5}

Distribution of single copy orthologs (SCOs) in the genomes of five species (Artocarpus heterophyllus, $A$. altilis, Morus notabilis, Arabidopsis thaliana and BARI Kanthal-3). (A) Venn diagram showing unique and shared SCOs in three genomes of Artocarpus species, M. notabilis and Arabidopsis. Each number represents a SCO gene family number. (B) Inferred phylogenetic tree constructed with SCOs from $A$. heterophyllus, $A$. altilis, M. notabilis, A. thaliana and BARI Kanthal-3 (A. heterophyllus) genomes. The tree was constructed using neighbor-joining (NJ) method with 100 bootstraps. 


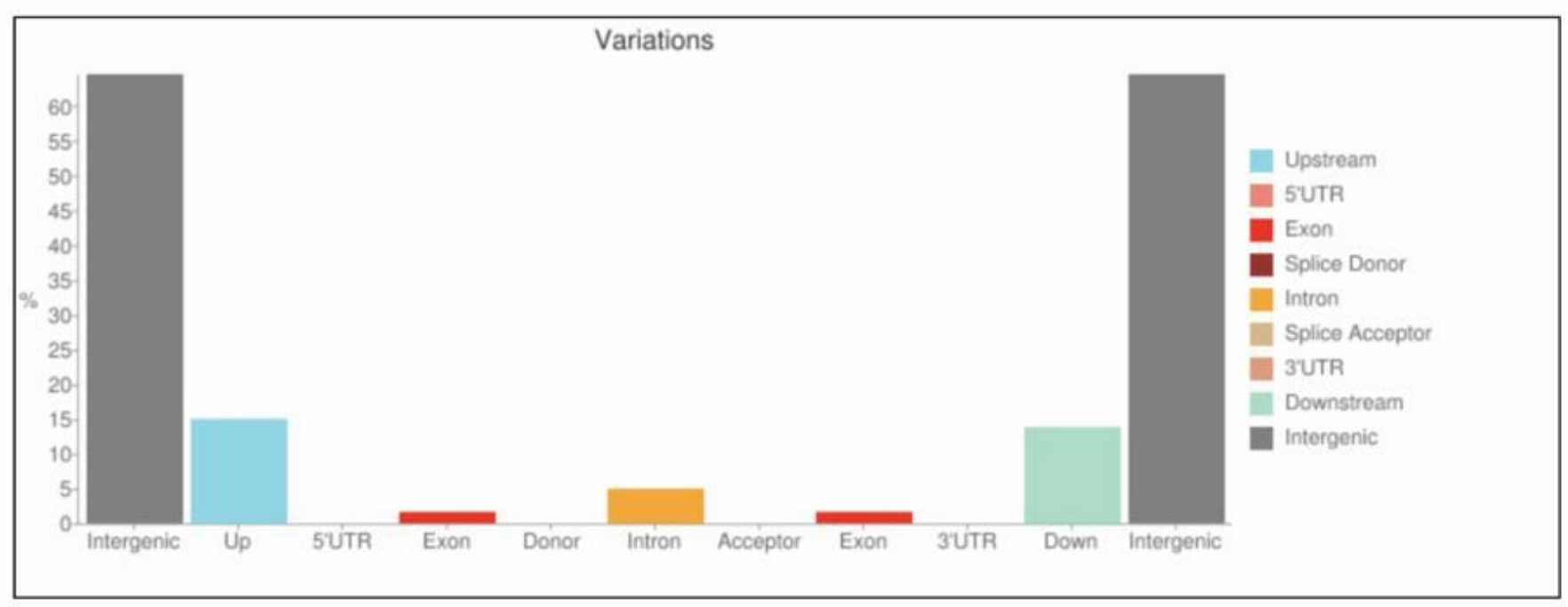

A

\begin{tabular}{|c|c|c|}
\hline \multicolumn{3}{|c|}{ Type } \\
\hline Type (alphabetical order) & Count & Percent \\
\hline downstream_gene_variant & $3,473,378$ & $13.817 \%$ \\
\hline intergenic_region & $16,202,023$ & $64.453 \%$ \\
\hline intron_variant & $1,266,335$ & $5.038 \%$ \\
\hline missense_variant & 232,587 & $0.925 \%$ \\
\hline splice_acceptor_variant & 1,558 & $0.006 \%$ \\
\hline splice_donor_variant & 1,597 & $0.006 \%$ \\
\hline splice_region_variant & 29,995 & $0.119 \%$ \\
\hline start_lost & 710 & $0.003 \%$ \\
\hline stop_gained & 4,750 & $0.019 \%$ \\
\hline stop_lost & 812 & $0.003 \%$ \\
\hline stop_retained_variant & 376 & $0.001 \%$ \\
\hline synonymous_variant & 162,857 & $0.648 \%$ \\
\hline upstream_gene_variant & $3,760,809$ & $14.961 \%$ \\
\hline
\end{tabular}

Figure 6

Variant annotation and effects of variant on genes. (A) Distribution and abundance of variants in the genome of BARI-Kanthal-3, and (B) Number of effects by type and region of the gene variants.

\section{Supplementary Files}


This is a list of supplementary files associated with this preprint. Click to download.

- Fig.S1.jpg 